\title{
Mortality from Parkinson's disease in China: Findings from a five-year follow up study in Shanghai
}

\author{
Gang Wang, Xin-Jian Li, Yi-Song Hu, Qi Cheng, Chun-Fang Wang, Qin Xiao, \\ Jun Liu, Jian-Fang Ma, Hai-Yan Zhou, Jing Pan, Yu-Yan Tan, Ying Wang, \\ Sheng-Di Chen
}

\begin{abstract}
Introduction: The mortality of Parkinson's disease (PD) and its associated risk factors among clinically definite PD patients in China has been rarely investigated. Our study aimed to identify the mortality rates and predictors of death in PD patients in China. Methods: 157 consecutive, clinically definite PD patients from the urban area of Shanghai were recruited from a central hospital based movement disorder clinic in 2006. All patients were regularly followed up at the clinic until December 31, 2011, or death. Mortality and associations with baseline demographics, health and medical factors were then determined within the cohort. Results: After 5 years, $11(7 \%)$ patients had died. The standardised mortality ratio was $0.62(95 \%$ CI 0.32 to $1.07, \mathrm{P}=0.104)$. The main causes of death were pneumonia $(54.5 \%, 6 / 11)$ and digestive disorders $(18.2 \%, 2 / 11)$, respectively. Age at onset, independent living, the mini mental state examination score, the Parkinson's disease sleep scale score and the Epworth sleepiness scale score at baseline were statistically significantly different between the survival group and the deceased group $(P<0.05)$. Across all participants, risk factors for death included low mini mental state examination score, and high Epworth sleepiness scale score according to a binary variable logistic regression analysis. Conclusions: This study confirms the similar survival of patients with PD to the control population up to a follow-up of 5 years. Interventions tailored to potential risk factors associated with death may offer further benefits.
\end{abstract}

RÉSUMÉ: Mortalité due à la maladie de Parkinson en Chine : observations tirées d'une étude de suivi à Shanghai. Introduction : En Chine, la mortalité due à la maladie de Parkinson (MP) et les facteurs qui y sont associés, chez les patients atteints de la MP dont le diagnostic clinique est certain, ont rarement été étudiés. Notre étude visait à identifier les taux de mortalité et les variables explicatives de la mortalité chez des patients atteints de la MP en Chine. Méthode : Cent cinquante-sept patients consécutifs atteints de la MP, dont le diagnostic était certain au point de vue clinique et résidant dans la zone urbaine de Shanghai, ont été recrutés dans une clinique des troubles du mouvement d'un hôpital central de la ville en 2006. Tous les patients ont été suivis régulièrement à la clinique jusqu'au 31 décembre 2011 ou jusqu'à leur décès. Les associations entre la mortalité et les caractéristiques démographiques au début du suivi, les facteurs de santé et les facteurs médicaux notés au cours du suivi de la cohorte ont été analysées. Résultats : Après 5 ans, 11 patients (7\%) étaient décédés. Le ratio normalisé de mortalité était de 0,62 (95\% IC de 0,32 à 1,$07 ; p=0,104)$. Les principales causes de décès étaient la pneumonie $(54,5 \%, 6 / 11)$ et les maladies digestives $(18,2 \%, 2 / 11)$. L'âge de début, l'autonomie, le score au mini-examen de l'état mental, le score du sommeil de la maladie de Parkinson et le score initial à l'échelle de somnolence diurne d'Epworth étaient significativement différents au point de vue statistique entre le groupe de patients qui étaient toujours vivants par rapport au groupe de patients décédés $(\mathrm{p}<0,05)$. Parmi tous les participants, les facteurs de risque de décès incluaient un score bas au mini-examen de l'état mental et un score élevé à l'échelle de somnolence diurne d'EPworth, selon une analyse de régression logistique binaire. Conclusions : Cette étude confirme que la survie des patients atteints de la MP est similaire à celle d'une population témoin au cours d'un suivi de 5 ans. Des interventions ciblant les facteurs de risque potentiels associés au décès pourraient offrir des bénéfices additionnels à ces patients.

Keywords: Cognitive impairment, excessive daytime sleepiness, mortality, Parkinson's disease

doi:10.1017/cjn.2015.49

Can J Neurol Sci. 2015; 42: 242-247

As the second most common neurodegenerative disorder, Parkinson's disease (PD) is characterized by the classic motor symptoms of tremor, rigidity, bradykinesia and postural instability, thought to be associated with increased mortality compared with the general populations. Previous studies have revealed varied standardised mortality ratios (SMRs) in patients with PD in both clinical and population-based cohorts. SMRs have been found to range from 0.80 to $3.50 .^{1-11}$ Especially in the postlevodopa era, the SMR from a few investigations have been found
From the Department of Neurology \& Institute of Neurology (GW, QC, QX, JL, JM, HZ, JP, YT, YW, SC), Rui Jin Hospital affiliated to Shanghai Jiao Tong University School of Medicine; Shanghai Municipal Center for Disease Control and Prevention (XL, CW), Shanghai; National Survey Research Center (YH), Renmin University of China, Beijing, China. Received November 1, 2014. Final Revisions Submitted March 20, 2015. Correspondence to: Dr Sheng-Di Chen, Department of Neurology \& Institute of Neurology, Rui Jin Hospital affiliated to Shanghai Jiao Tong University School of Medicine, Shanghai, 200025 China. E-mail: chen_sd@medmail.com.cn; or, Dr Ying Wang, Department of Neurology \& Institute of Neurology, Rui Jin Hospital affiliated to Shanghai Jiao Tong University School of Medicine, Shanghai, 200025 China.

E-mail: wangying@ medmail.com.cn 
to demonstrate a trend to "super-normal" survival rather than excess mortality. ${ }^{3-12}$ Except for a recent report from Chinese Hong Kong, ${ }^{3}$ there is no SMR data from mainland China where levodopa has been used extensively for at least two decades. Hence, confirming the SMR and associated factors with death would be particularly beneficial for this country with a particularly large PD population. In fact, such analysis of mortality in PD patients will be valuable in understanding the natural course of PD and planning the distributions of health resources in China in the present and in the future.

We previously reported a series of cross-sectional clinical studies for motor symptoms and non-motor symptoms among hospital-based clinically definite PD patients. ${ }^{13-15}$ In the present study we used the same databases to identify SMR and factors associated with death.

\section{Methods \\ Participants}

All patients who have visited the movement disorder clinic at the Department of Neurology, Rui Jin Hospital affiliated to Shanghai Jiao Tong University School of Medicine, Shanghai, China, and are permanent residents in Shanghai, were recruited consecutively into the present study in 2006. This movement disorder clinic is the biggest referral centre for PD in Shanghai. Patients were referred from general practitioners, family physicians and emergency department doctors. As one of biggest clinical centers in China, the numbers of the patients with PD who visited our clinic annually numbered about five hundred before 2007. However, over half of the patients were from outside of Shanghai metropolis and not permanent residents. When they passed away, their residential city, rather than Shanghai metropolis, recorded information of their death certificates. The control populations for calculating SMR were also limited to the permanent residents of Shanghai. Patients who lived outside of Shanghai metropolis were excluded from the present study. The consecutive patients were identified with the UK PD Brain Bank criteria for the diagnosis of idiopathic PD. Exclusion criteria included a history of dementia or hallucinations within one year of onset of disease, features leading to a diagnosis other than idiopathic PD, or incomplete clinical information. All patients lived in the urban community of Shanghai and were sufficiently competent in Chinese to complete assessments. All participants were assessed at baseline, and 157 were followed in the clinic until December 31, 2011. Four individuals declined to participate in the five year follow up.

The study was approved by the Research Ethics Committee, Rui Jin Hospital affiliated to Shanghai Jiao Tong University School of Medicine, China. Written informed consent was obtained from each participant.

\section{Clinical assessment}

At baseline, face-to-face interviews were conducted to collect subjects' demographic information, living conditions, past and family medical history (especially cognitive impairment, hypertension, diabetes mellitus, hyperlipidemia, other co-morbidities, and medications, etc.), psychiatric history (depression, anxiety, insomnia, neurosis, etc.). Functional independence was assessed with caregivers' information and Activities of daily living (ADL) scores. The neurologists conducted their clinical assessment by applying the Hoehn and Yahr (H-Y) staging scale, the Mini-mental State Examination (MMSE), the Non-motor Symptoms Scale (NMSS), the Parkinson's Disease Sleep Scale (PDSS), the Epworth Sleepiness scale (ESS), the Geriatric Depression Scale (GDS), and the Hamilton Anxiety Scale (HAMA). In order to evaluate the relationship between survival and dopaminergic treatment, the daily levodopa equivalent dose (LDE) was calculated as described in a previous study. ${ }^{16}$ All data were gathered and screened for validity by senior movement disorders specialists.

\section{Ascertainment of vital status}

In January 2012, we confirmed the status of all patients. For those who had died, death certificates (cause and date of death) were obtained from the database of the Shanghai Municipal Center for Disease Control and Prevention, China. Diagnoses on the death certificate were registered using the international Classification of Disease ninth and tenth revision (ICD-9 and ICD-10). The primary causes of death were grouped into five different categories based on the ICD-9 classifications. ${ }^{17}$

\section{Statistical Analysis}

All data analyses were performed using SPSS statistical software. SMRs and corresponding 95\% confidence intervals (CI) were calculated as the ratios of the observed to the expected number of deaths for selected causes. The expected number was obtained by applying the age- and sex-specific mortality rates of the Chinese urban population in the period $2008-2012^{18}$ to the cohort under study. SMRs were calculated separately for the two genders, and overall. A Kaplan-Meier Survival Curve was used to assess the cumulative survival rate of PD patients.

Descriptive statistics were computed, the t-test or $\chi^{2}$ test were used to calculate differences between groups in continuous and categorical variables, respectively. To explore the potential associated factors for survival, factors with significant difference between two groups with $P<0.05$ were entered into binary variable logistic regression models that included age and sex and we identified the associated factors for death after adjusting for sex and age.

\section{Results}

\section{Sample Characteristics}

Among the 157 participants, $92(58.6 \%)$ were males and $65(41.4 \%)$ were females; the mean $(+/-$ standard deviation (SD)) age, in years, for males was $65.48 \pm 9.37$ and for females, $65.46 \pm 11.58$; the mean (SD) age in years at onset for males: $60.79 \pm 10.23$ and for females: $59.04 \pm 12.10(P>0.05))$. The average disease duration at baseline is $5.47 \pm 0.35$ years (Mean \pm standard error (SE)). The average $\mathrm{H}-\mathrm{Y}$ stage was $1.96 \pm 0.7$ (Mean $\pm \mathrm{SD}$ ), and average MMSE score was 26.31 \pm 3.59 (Mean \pm SD). Patients with a MMSE score $<24$ were $11.5 \%$ $(18 / 157)$ of the sample at baseline. Education more than 12 years was attained by $51.6 \%(81 / 157)$ of the subjects. Patients able to maintain the ability of independent living made up $82.8 \%$ (130/157) of the population studied. The LDE among the patients was $339.75 \pm 18.10($ Mean $\pm \mathrm{SE}) \mathrm{mg} /$ day and there was a positive association between $\mathrm{H}-\mathrm{Y}$ stage and $\operatorname{LDE}(P<0.01)$. An ESS score of over 10 was found to be present in 5.7\% (9/157) of PD patients at baseline. Of these, $44.6 \%(70 / 157)$ patients had at least one additional chronic disease such as hypertension or diabetes. 
Table 1: Standardized mortality ratios and corresponding $95 \%$ confidence intervals calculated as the ratios of the observed to the expected number of deaths for selected causes

\begin{tabular}{|c|c|c|c|c|c|c|}
\hline & ICD-9 codes & Sex & Observed & Expected* & SMR & $95 \% \mathrm{CI}$ \\
\hline \multirow[t]{3}{*}{ All cause } & & Total & 11 & 17.88 & 0.62 & $0.32-1.07$ \\
\hline & & M & 4 & 20.75 & 0.19 & $0.06-0.46$ \\
\hline & & $\mathrm{F}$ & 7 & 13.68 & 0.51 & $0.22-1.01$ \\
\hline \multirow[t]{3}{*}{ Respiratory disorders } & $460-519$ & Total & 6 & 2.10 & 2.86 & $1.16-5.94$ \\
\hline & & M & 3 & 2.80 & 1.07 & $0.27-2.92$ \\
\hline & & $\mathrm{F}$ & 3 & 1.54 & 1.94 & $0.50-5.30$ \\
\hline \multirow[t]{3}{*}{ Digestive disorders } & $520-579$ & Total & 2 & 0.430 & 4.65 & $0.78-15.37$ \\
\hline & & M & 0 & 0.52 & 0 & - \\
\hline & & $\mathrm{F}$ & 2 & 0.35 & 5.71 & $0.96-18.88$ \\
\hline \multirow[t]{3}{*}{ Cardiac disorders } & $390-429$ & Total & 1 & 3.53 & 0.28 & $0.01-1.40$ \\
\hline & & M & 0 & 4.02 & 0 & - \\
\hline & & $\mathrm{F}$ & 1 & 3.10 & 0.32 & $0.02-1.59$ \\
\hline \multirow[t]{3}{*}{ Stroke } & $430-438$ & Total & 1 & 3.61 & 0.28 & $0.01-1.16$ \\
\hline & & M & 1 & 4.27 & 0.23 & $0.01-1.16$ \\
\hline & & $\mathrm{F}$ & 0 & 3.04 & 0 & - \\
\hline \multirow[t]{3}{*}{ Undetermined diagnosis or cause } & 799 & Total & 1 & 0.10 & 10.00 & $0.50-49.32$ \\
\hline & & M & 0 & 0.12 & 0 & - \\
\hline & & $\mathrm{F}$ & 1 & 0.07 & 14.29 & $0.71-70.46$ \\
\hline
\end{tabular}

Abbreviations and symbols: $\mathrm{SMR}=$ standardized mortality ratio; $\mathrm{CI}=$ corresponding $95 \%$ confidence interval.

*The expected number was obtained by applying to the cohort under study the age- and sex-specific mortality rates of the Chinese urban population (resource from: China Public Health Statistical Yearbook (2008-2013))

\section{SMR, cause of death and survival duration}

A total of eleven (7\%) patients died, of whom six $(3.8 \%)$ died of pneumonia, two $(1.3 \%)$ died of digestive disorders, one $(0.6 \%)$ died of cardiac attack, one $(0.6 \%)$ died of stroke, and one died suddenly with unknown cause at the endpoint. Standardised mortality ratios was only 0.62 (95\% CI 0.32 to $1.07, P=0.104)$ comparable with an age- and sex-matched Chinese urban population over the same period. Even though the findings were based on small numbers, the relative risks were particularly high for death from pneumonia $(\mathrm{SMR}=2.86)$ and from digestive disorders $(\mathrm{SMR}=4.64)$ (Table 1$)$. Additionally, the survival durations between independent living and dependent living, rather than male and female, longer education and low education, are significantly different $(P<0.01)$ (Figure).
A

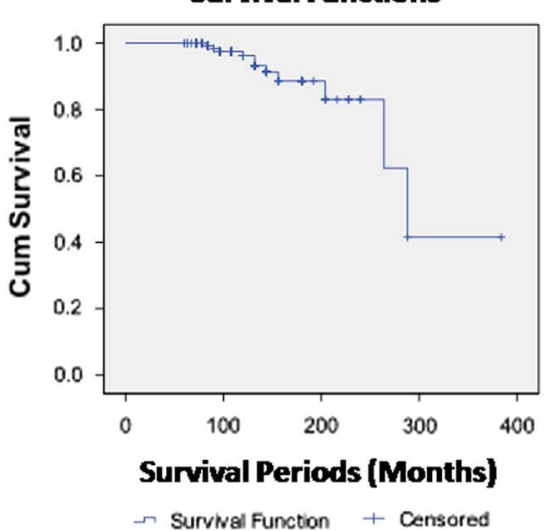

B

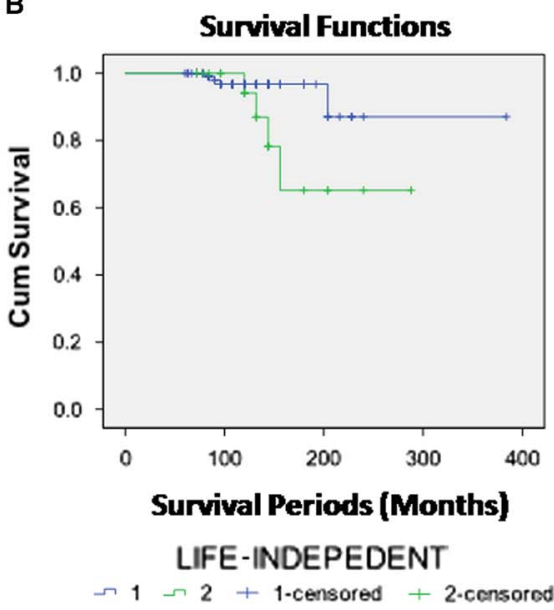

Figure: Survival of 157 patients with PD. A: The survival durations of the total sample. B: Different survival between dependent (2) and independent living (1) patients with PD. 
Table 2: Baseline Characteristics for survival and death patients with PD

\begin{tabular}{|c|c|c|c|}
\hline Characteristic & Survival group $(n=146)$ & Deceased group $(n=11)$ & $P$ \\
\hline Age $($ Mean $\pm S D)$, years & $64.76 \pm 10.26$ & $74.91 \pm 4.97$ & 0.000 \\
\hline Age (Mean \pm SD) at onset, Years & $59.55 \pm 11.15$ & $66.95 \pm 6.61$ & 0.004 \\
\hline Males, n (\%) & $88 / 146(60.27)$ & $4 / 11(36.36)$ & 0.121 \\
\hline Education (>12 years),n (\%) & $77 / 146(52.74)$ & 4/11(36.36) & 0.295 \\
\hline $\mathrm{H}-\mathrm{Y}$ stage $(\mathrm{Mean} \pm \mathrm{SD})$ & $1.94 \pm 0.77$ & $2.32 \pm 0.72$ & 0.114 \\
\hline LDE $($ Mean \pm SE) $(\mathrm{mg} /$ day $)$ & $338.21 \pm 18.78$ & $360.23 \pm 71.09$ & 0.757 \\
\hline Independent living, $\mathrm{n}(\%)$ & $126 / 146(86.30)$ & 4/11(36.36) & 0.000 \\
\hline MMSE $($ Mean \pm SD) & $26.66 \pm 3.13$ & $21.55 \pm 5.66$ & 0.014 \\
\hline NMSS (Mean \pm SE) & $30.18 \pm 2.38$ & $63.45 \pm 20.29$ & 0.134 \\
\hline GDS (Mean \pm SE) & $12.90 \pm 1.05$ & $17.00 \pm 5.02$ & 0.352 \\
\hline HAMA (Mean \pm SE) & $9.29 \pm 0.65$ & $13.00 \pm 3.64$ & 0.181 \\
\hline ESS $($ Mean \pm SE) & $3.21 \pm 0.31$ & $8.09 \pm 1.97$ & 0.033 \\
\hline PDSS $($ Mean \pm SE) & $117.52 \pm 2.38$ & $87.88 \pm 14.99$ & 0.006 \\
\hline
\end{tabular}

$\mathrm{PD}=$ Parkinson's disease, $\mathrm{SD}=$ standard deviation, $\mathrm{H}-\mathrm{Y}=$ Hoehn \& Yahr, LDE = levodopa equivalent dose, MMSE = Mini Mental State Examination, NMSS = Non-motor Symptoms Scale, GDS = Geriatric Depression Scale, HAMA = Hamilton Anxiety Scale, ESS = Epworth Sleepiness Scale, PDSS $=$ Parkinson's Disease Sleep Scale.

\section{Related factors of death}

The risk factors associated with death are shown in Table 2. Age at onset, independent living, MMSE score, PDSS score and ESS scores were factors that produced statistically significant differences between the survival group and the deceased group $(P<0.05)$.

The odds of associations before and after adjustment for age and sex between groups are shown in Table 3. In both models,

Table 3: Baseline factors associated with death adjusted for age and sex

\begin{tabular}{l|c|c|c}
\hline Outcome and factor & B & SE & $\boldsymbol{P}$ \\
\hline Age at onset & & & \\
\hline Unadjusted & 0.063 & 0.050 & 0.206 \\
\hline Adjusted for age and sex & 0.000 & 0.134 & 0.999 \\
\hline Independent living & & & \\
\hline Unadjusted & 0.747 & 0.928 & 0.421 \\
\hline Adjusted for age and sex & 0.607 & 0.986 & 0.538 \\
\hline MMSE & & & \\
\hline Unadjusted & -0.233 & 0.103 & 0.023 \\
\hline Adjusted for age and sex & -0.246 & 0.108 & 0.023 \\
\hline ESS & & & \\
\hline Unadjusted & 0.215 & 0.099 & 0.030 \\
\hline Adjusted for age and sex & 0.212 & 0.101 & 0.035 \\
\hline PDSS & & & \\
\hline Unadjusted & -0.002 & 0.016 & 0.890 \\
\hline Adjusted for age and sex & 0.002 & 0.019 & 0.907 \\
\hline
\end{tabular}

Multivariable association between survival patients and death patients by logistic regression

$\mathrm{B}=$ Regression coefficient, $\mathrm{SE}=$ Standard error, MMSE $=$ Mini Mental State Examination, ESS = Epworth Sleepiness Scale, PDSS = Parkinson's Disease Sleep Scale. low MMSE score and high ESS score were identified as predictive factors.

Further, we examined the potential predictive effect of daytime somnolence on mortality, after adjusting for the effect of cognitive impairment. We found that there was a negative correlation between ESS score and MMSE score $(\mathrm{P}<0.05$ and we identified ESS as a predictive factor after adjusting $\operatorname{MMSE}(\mathrm{B}=0.013$, $\mathrm{SE}=0.005, \mathrm{P}=0.007)$.

\section{Discussion}

Previously, few studies focused on assessing survival in PD cohorts from follow-up studies in China. In the present study, we identified a super-normal survival of patients with PD to the control populations over five years follow-up and also identified risk factors for poor survival, including low MMSE score and high ESS score and we found that cognitive impairment and excessive daytime sleepiness are potential predictors of death.

\section{SMR and cause of death}

Although some studies report survival time, SMRs allow comparison between population groups with different demographics and life expectancies. ${ }^{11}$ The SMR of this cohort was 0.62 (95\% CI 0.32 to 1.07 ), implying that the five year mortality ratio of the patients with PD was not significantly higher than the ratio of the general urban Chinese population. The SMR in the present study is consistent with the survival data from the highly selected subjects in the DATATOP study (eight years of follow-up $\mathrm{SMR}=0.80)^{12}$ and an Austrian study carried out by DiemZangerl and his co-workers (five years of follow-up $\mathrm{SMR}=0.6$; 10 years of follow-up SMR $=0.9),{ }^{4}$ and very close to the previous investigation from Hong Kong (10 years follow-up SMR = 1.1). ${ }^{3}$

With respect to differences of the follow-up periods and ethnicities, we believe that there are several reasons why our cohort had a better survival compared to the prior studies. Firstly, the selection criteria and diagnostic accuracy in the present study 
ensure the samples were comprised of idiopathic PD rather than Parkinsonism with atypical features, therefore the recruited patients had a better prognosis and longer survival time. In recent years, the majority of the movement disorder specialists in China have regularly adopted the Chinese guideline for the diagnosis and treatment of PD and have significantly improved their ability to make the diagnosis and use best practice in the management of $\mathrm{PD} ;{ }^{19}$ Secondly, clinically based samples may benefit from input from movement disorder specialists compared with communityascertained cases, including optimal treatment and psychological counselling. Over the last two decades medications available in urban China have almost approached the level found in Western countries, including complex levodopa preparations, non-ergot dopamine agonists, monoamine oxidase B typed (MAO-B) inhibitors, catechol-O-methyltransferase (COMT) inhibitors and so on. ${ }^{16,19}$ Thirdly, the relatively short follow-up period may be expected to lower the SMR compared to previous surveys with more than ten years of observation. ${ }^{4,7}$ Some cohort studies have suggested that SMRs will increase with time. ${ }^{4,5,20}$ Therefore it is likely that our cohort would have a higher SMR if observed over a period longer than five years.

Similar to most previous studies ${ }^{6,21}$ pneumonia (6/11) was the most common cause of death, followed by digestive disorders (peritonitis, and gastrointestinal bleeding, 2/11), acute coronary syndrome (1/11), stroke (1/11), and sudden death of unknown cause (1/11). It is important to note that no malignancy occurred, ${ }^{4-21}$ which has a mortality rate/100000 of about 174 in the normal Chinese urban population. ${ }^{18}$ Accounting for over $50 \%$ of the deaths, pneumonia is associated with limited mobility, swallowing impairment, and reduced ability to expectorate. ${ }^{21,22}$ However, apart from the current studies, digestive disorders are seldom reported as a cause of death. Non-motor symptoms such as dysfunction of the gastrointestinal system including dysphagia, impaired gastric emptying, decreased bowel movement frequency, and difficulty defecating occur during any stage of PD and may increase the risk of subsequent chronic infection and inflammation in the gastrointestinal tract. ${ }^{23}$ Such theories need to be further tested. Additionally, we found that there are different survival durations between dependent and independent living patients with PD. By contrast, the survival durations between male and female, high education and low education, show no significant difference. High Quality of life (QoL) may have the benefit of increasing survival for patients with PD.

\section{Associated factors as predictor of death}

The present study shows that low MMSE score at baseline was related to an increased risk of death among $\mathrm{PD}$ patients $(\mathrm{B}=-0.246, \mathrm{SE}=0.108, \mathrm{P}=0.02395 \% \mathrm{CI}: 0.63-0.97)$. The results are in accordance with the previous observations, which indicated that PD patients with cognitive impairment have a particularly high risk of mortality ${ }^{3,7,9}$ and cognitive impairment is an independent predictor of decreased survival in PD. ${ }^{24,25}$ It is wellknown that cognitive impairment, especially Parkinson's disease dementia (PDD), occurs in $24 \%$ to $31 \%$ of PD patients, ${ }^{26}$ and both reduced cholinergic activity in the cortex and the spread of fibrillar $\alpha$-synuclein ( $\alpha$-syn) pathology are thought to be the crucial mechanisms responsible for the development of PDD. ${ }^{23,27}$ Furthermore, the neocortical $\alpha$-synuclein pathology may confer a worse prognosis. Our results support the common hypothesis for PD with cognitive impairment as a predictor of death. The molecular pathological mechanism needs to be addressed in more detail in the future.

In the present study, $5.7 \%$ of the study participants with ESS score $>10$ had regular or frequent excessive daytime sleepiness (EDS), one of most common symptoms. ${ }^{28}$ We found that a high ESS score at baseline was associated with an increased risk of death among $\mathrm{PD}$ patients $(\mathrm{B}=0.212, \mathrm{SE}=0.101, \mathrm{P}=0.035$ 95\% CI: 1.02-1.51), which has been rarely reported from previous similar studies. As a frequent complaint among PD patients, EDS was found to be present in $5.6 \%$ of PD patients at baseline, $22.5 \%$ at four years, and $40.8 \%$ at eight years. ${ }^{29}$ The etiology of EDS in PD may be the disease process, medications, or other sleep disorders. EDS may be related to dopaminergic medications and is more commonly associated with dopamine agonists than levodopa. ${ }^{23}$ One recent study suggested that EDS was associated with an increased risk of dementia, ${ }^{30}$ and EDS may indirectly increase risk of mortality by effect of dementia. There also existed a potential predictive effect of daytime somnolence on mortality, after adjusting for the effect of cognitive impairment, in the present study. Before our study, there were no direct reports of a relationship between EDS and mortality in PD. Regarding primary prevention of EDS through regular exercise and strategically planned naps etc., may potentially lead to a decrease in mortality. Additionally, some interesting possible factors, including age at onset, independent living, and PDSS score showed potential with $P$ value $<0.05$ in the present study. However, there were no significant differences between the two groups by a double variable logistic regression analysis.

\section{Limitations}

Our study is limited by its clinical based samples with a relatively short follow-up period, which has the potential for selection bias, attenuating the power to assess the influences of associated factors on death. Consecutive follow-up, over ten or twenty years, is planned. Secondly, we assessed sleep disorders, including EDS, only by ESS rather than polysomnography. Furthermore, the factors associated with death reported here are values taken at baseline and do not take into account possible changes in some factors over time. Therefore, future prospective studies should investigate mortality with a longer follow up period and more sophisticated analytical methods.

\section{Conclusions}

This study confirms the similar survival of patients with PD to the control population up to a follow-up of five years. However, cognitive impairment, and EDS at the baseline are associated with death. Interventions tailored to potential risk factors associated with death may offer further benefits.

\section{ACKNOWLEDGEMENTS}

This study was granted by the National Program of Basic Research of China (2011CB504104) and the National Natural Science Foundation (81371407). The authors thank patients, doctors and nurses in the clinic who were involved in the study. We thank Dr. Jeremy Stern at Department of Neurology, St. George's Hospital and Medical School, London, United 
Kingdom, for his proof-reading. We also thank Prof. Anthony E Lang at Morton and Gloria Shulman Movement Disorders Center, Toronto Western Hospital, Ontario, Canada, for critical reading and comments on this manuscript.

\section{Disclosures}

The authors do not have anything to disclose.

\section{REFERENCES}

1. Ben-Shlomo Y, Head J, Lees AJ. Mortality in DATATOP. Annal Neurol. 1999;45:138-9.

2. Chen H, Zhang SM, Schwarzschild MA, Hernan MA, Ascherio A. Survival of Parkinson's disease patients in a large prospective cohort of male health professionals. Mov Disord. 2006;21: $1002-7$.

3. Auyeung M, Tsoi TH, Mok V, et al. Ten year survival and outcomes in a prospective cohort of new onset Chinese Parkinson's disease patients. J Neurol Neurosurg Psychiatry. 2012; 83:607-11.

4. Diem-Zangerl A, Seppi K, Wenning GK, et al. Mortality in Parkinson's disease: a 20-year follow-up study. Mov Disord. 2009;24:819-25.

5. Hely MA, Morris JG, Traficante R, Reid WG, O'Sullivan DJ, Williamson PM. The Sydney multicentre study of Parkinson's disease: progression and mortality at 10 years. J Neurol Neurosurg psychiatry. 1999;67:300-7.

6. Mylne AQ, Griffiths C, Rooney C, Doyle P. Trends in Parkinson's disease related mortality in England and Wales, 1993-2006. Eur J Neurol. 2009;16:1010-6.

7. Posada IJ, Benito-Leon J, Louis ED, et al. Mortality from Parkinson's disease: a population-based prospective study (NEDICES). Mov Disord. 2011;26:2522-9.

8. Ben-Shlomo Y, Marmot MG. Survival and cause of death in a cohort of patients with parkinsonism: possible clues to aetiology? J Neurol Neurosurg Psychiatry. 1995;58:293-9.

9. Hughes TA, Ross HF, Mindham RH, Spokes EG. Mortality in Parkinson's disease and its association with dementia and depression. Acta Neurol Scand. 2004;110:118-23.

10. Herlofson K, Lie SA, Arsland D, Larsen JP. Mortality and Parkinson disease: A community based study. Neurology. 2004;62: 937-942.

11. Ishihara LS, Cheesbrough A, Brayne C, Schrag A. Estimated life expectancy of Parkinson's patients compared with the UK population. J Neurol Neurosurg Psychiatry. 2007;78:1304-9.

12. Mortality in DATATOP: a multicenter trial in early Parkinson's disease. Parkinson Study Group. Ann Neurol. 1998;43:318-25.

13. Wang G, Hong Z, Cheng Q, et al. Validation of the Chinese non-motor symptoms scale for Parkinson's disease: results from a Chinese pilot study. Clin Neurol Neurosurg. 2009;111: 523-526.
14. Wang G, Cheng Q, Zeng J, et al. Sleep disorders in Chinese patients with Parkinson's disease: validation study of a Chinese version of Parkinson's disease sleep scale. J Neurol Sci. 2008;271:153-7.

15. Chen W, Chen S, Kang WY, et al. Application of odor identification test in Parkinson's disease in China: a matched case-control study. J Neurol Sci. 2012;316:47-50.

16. Wang G, Cheng Q, Zheng R, et al. Economic burden of Parkinson's disease in a developing country: a retrospective cost analysis in Shanghai, China. Mov Disord. 2006;21:1439-43.

17. World Heath Organization. Manual of the international classification of disease injuries and causes of death 9th revision. Geneva: World Health Organization; 1978.

18. Mortality Data Bank of China urban, 2008-2012, China Public Health Statistical Yearbook (2008-2013). URL: http://www. nhfpc.gov.cn/htmlfiles/zwgkzt/ptjnj/year2008-2012.

19. Chen W, Chen S, Xiao Q, Wang G, Chen SD. Current clinical practice for Parkinson's disease among Chinese physicians, general neurologists and movement disorders specialists: a national survey. BMC Neurol. 2012;12:155.

20. Hely MA, Morris JG, Reid WG, Trafficante R. Sydney Multicenter Study of Parkinson's disease: non-L-dopa-responsive problems dominate at 15 years. Mov Disord. 2005;20:190-9.

21. Pennington S, Snell K, Lee M, Walker R. The cause of death in idiopathic Parkinson's disease. Parkinsonism Rel Disord. 2010; 16:434-7.

22. Monteiro L, Souza-Machado A, Pinho P, Sampaio M, Nobrega AC, Melo A. Swallowing impairment and pulmonary dysfunction in Parkinson's disease: The silent threats. J Neurol Sci. 2014;339:149-52.

23. Chen W, Xu ZM, Wang G, Chen SD. Non-motor symptoms of Parkinson's disease in China: a review of the literature. Parkinsonism Rel Disord. 2012;18:446-52.

24. de Lau LM, Verbaan D, Marinus J, van Hilten JJ. Survival in Parkinson's disease. Relation with motor and non-motor features. Parkinsonism Rel Disord. 2014;20:613-6.

25. Xu J, Gong DD, Man CF, Fan Y. Parkinson's disease and risk of mortality: meta-analysis and systematic review. Acta Neurol Scand. 2014;129:71-9.

26. Aarsland D, Zaccai J, Brayne C. A systematic review of prevalence studies of dementia in Parkinson's disease. Mov Disord. 2005;20:1255-63.

27. Irwin DJ, Lee VM, Trojanowski JQ. Parkinson's disease dementia: convergence of alpha-synuclein, tau and amyloid-beta pathologies. Nat Rev Neurosci. 2013;14:626-36.

28. Chen HL, Zhao EJ, Zhang W, et al. Meta-analyses on prevalence of selected Parkinson's nonmotor symptoms before and after diagnosis. Transl Neurodegener. 2015;4:1

29. Gjerstad MD, Alves G, Wentzel-Larsen T, Aarsland D, Larsen JP. Excessive daytime sleepiness in Parkinson disease: is it the drugs or the disease? Neurology. 2006;67:853-8.

30. Zhu K, van Hilten JJ, Marinus J. Predictors of dementia in Parkinson's disease; findings from a 5-year prospective study using the SCOPA-COG. Parkinsonism Rel Disord. 2014;20:980-5. 